Furić, K., Mohaček-Grošev, V., Hadžija, M. (2005), "Development of cataract caused by diabetes mellitus: Raman study" Journal of Molecular Structure, Vol. 744-747, pp. 169-177.

\title{
Development of cataract caused by diabetes mellitus: Raman study
}

\author{
Krešimir Furić ${ }^{\mathrm{a} *}$, Vlasta Mohaček-Grošev ${ }^{\mathrm{a}^{*}}$, Mirko Hadžija $^{\mathrm{b} *}$
}

\begin{abstract}
Diabetes mellitus succeeded by diabetic cataract was induced to experimental animals (Wistar rats) by applying an Alloxan injection. Eye properties deterioration were monitored from clinical standpoint and using Raman and infrared spectroscopies. All cases of developed cataract were followed by important changes in vibrational spectra, but Raman spectroscopy proved to be more useful because of larger number of resolved bands. Each $k$ th Raman spectrum of diseased lens (in our notation $k$ denotes disease age and cataract degree as described in chapter Alloxan diabetes) can be expressed as a sum of the Raman spectrum of healthy lens, $I_{R}$, multiplied by a suitable constant $c_{\mathrm{k}}$, and the fluorescent background spectrum, $\mathrm{I}_{\mathrm{FB}}$. We introduce the ratio of integrated intensities $I_{\mathrm{FB}}$ and $c_{\mathrm{k}} * I_{\mathrm{R}}$ as a physical parameter called fluorescent background index $\mathrm{F}_{\mathrm{FB}}$. It turns out that $F_{\mathrm{FB}}$ grows as cataract progresses and has its maximum at approx. 4 , whence it decreases. $F_{\mathrm{FB}}$ values are larger for $200-1800 \mathrm{~cm}^{-1}$ spectral interval than for $2500-4000 \mathrm{~cm}^{-1}$ interval.
\end{abstract}

In the same manner another quantity called water band index $F_{\mathrm{W}}$ is defined for each Raman spectrum of diseased lens in the $2800-3730 \mathrm{~cm}^{-1}$ interval. It is the ratio of the integrated intensity from 3100 to $3730 \mathrm{~cm}^{-1}$ (water band interval) divided by the integrated intensity of the $2800-3100 \mathrm{~cm}^{-1}$ interval $\left(\mathrm{C}-\mathrm{H}\right.$ stretching region). $F_{\mathrm{W}}$ increases monotonously with cataract progression with maximum at the end of monitored period ( 5 months).

These two indices helped us to formulate a model describing disease development from the earliest molecular changes to its macroscopic manifestation. As glucose and other small saccharide molecules enter the lens tissue, they bind to crystallin and other proteins via $\mathrm{O}$ - and $\mathrm{S}$ glycosidic linkages which occur probably at tyrosine and cystein sites. In Raman spectrum this corresponds to broad bands at 540 and $1100 \mathrm{~cm}^{-1}$ which grow together with the fluorescent background, because both contributions originate in nonenzimatically glycated proteins. The maximum of possible binding ends after approximately 4 months (cataract degree 4 ), but the water continues to enter the tissue and resides in water agglomerates.

The lens impairing caused by fluorescent light scattering on aberrant glycoproteins and other fluorescent centers appears first and is usually associated with the ageing cataract, while deterioration of lens properties caused by increased binding of water steadily rises with glucose

\footnotetext{
${ }^{a}$ Molecular Physics Laboratory, Department for Material Physics, Ruđer Bošković Institute, Bijenička 54, P.O. Box 180, 10002 Zagreb, Croatia (kfuric@irb.hr, mohacek@irb.hr)

${ }^{\mathrm{b}}$ Laboratory for Experimental Diabetes, Department for Molecular Medicine, Ruđer Bošković Institute, Bijenička 54, P.O. Box 180, 10002 Zagreb, Croatia (hadzija@irb.hr)
} 
Furić, K., Mohaček-Grošev, V., Hadžija, M. (2005), "Development of cataract caused by diabetes mellitus: Raman study" Journal of Molecular Structure, Vol. 744-747, pp. 169-177.

and is characteristic of diabetic cataract. This interpretation is in agreement with electron microscopy results of other groups and with our preliminary findings obtained with light microscopy.

\section{Keywords}

Diabetes; Eye-lens; Cataract; Raman spectroscopy

\section{Introduction}

The majority of reported cataracts fall in the category of senile cataract (85\%) [1]. Among other severe causes influencing lens opacity such as drugs, irradiation by UV or ionized light, traumatic injuries, inflammation diseases and others, diabetes is certainly among the widely spread.

Diabetes is commonly occurring malady causing the number of diseased to increase in each succeeding generation by about $3 \%$, with retinopathy as the most frequent specific complication. At the time of diagnosis less than 5\% of patients have retinopathy. After 10 years of manifest diabetes the prevalence to retinopathy intensifies to $40-50 \%$ and, after 20 years more than $90 \%$ of patients have some retinal abnormality. In many of them the natural course of events is accelerated by poor control of rather permanent hyperglycaemia, and often serious secondary complications.

It is well known that unique optical properties of the eye lens strongly depend on packing arrangements of fibrous proteins called crystallins, which provide optically homogeneous structural layers less than $20 \mathrm{~nm}$ apart [1]. These fibres are encapsuled by a layer of epithaxial cells from the anterior side, perpendicularly to the optical axis of the lens, and contain a bunch of embrionic fibres at the lens center [2]. Thus in every lens the central part is the oldest one, and the youngest fibres are at the periphery (cortex). Lens contains no blood capillaries, and the metabolism in such tissues is conducted via direct membrane contacts [3]. Specific nature of these contacts in lens is not known, but they take up as much as 50-60\% of membrane surface compared to only 3-4\% in other tissues [1]. Recent research focused on the role intermediate filament proteins (in particular CP49 protein) play in formation and maintenance of lens skeleton [4].

Vibrational spectroscopies, Raman and infrared, have been extensively used in biology and medicine as analytic and diagnostic tools from their early beginnings [5], [6], [7] and [8]. Rapid computerisation and the discovery of laser accelerated the number of these studies reported in books and conference proceedings [9], [10] and [11]. The application of vibrational spectroscopies in the eye research focused mainly of the lens and cornea. Pioneer work from 
Furić, K., Mohaček-Grošev, V., Hadžija, M. (2005), "Development of cataract caused by diabetes mellitus: Raman study" Journal of Molecular Structure, Vol. 744-747, pp. 169-177.

early 1970s [12], [13], [14] and [15] broadened and intensified and presently encompasses even very specialized topics such as artificial lenses [16] or organ cultured cornea [17].

Biochemical markers of early eye lens changes characterizing diabetic microangiopathy and progressive development of cataract are not completely understood. The presence of aldose reductase and the accumulation of sorbitol in the lens of diabetic animals have been observed for a long time [18]. It has been shown that many of the lens changes stem from osmolarity effect caused by sorbitol and galactose [19]. On the other hand the function of sorbitol in diabetic complications of different tissues was proved insignificant by further investigation [20].

The current hypothesis of diabetic cataract formation considers it to be a consequence of nonenzymatic glycosylation of lens proteins [21], [22], [23] and [24]. Formation of Schiff's bases between glucose and amino groups of proteins was recognised [25] and an Amadori rearrangement to a more stable ketoamino structure was noticed [26].

In this study we have investigated development of diabetic cataract in the rat lens with Raman and infrared spectroscopy during 5 months. The degree of cataract formation of each rat lens was determined by observation of progressive damage of iris blood vessels.

\section{Research design and methods}

\subsection{Alloxan diabetes, catarct development}

Adult male Wistar rats, 2 months of age, weighting 190-230 g, were housed in cages with food and water ad libitum, in temperature controlled room $\left(22^{\circ} \mathrm{C}\right)$ with 12 -h light-dark cycle. Diabetes was induced by single injection of alloxan $(75 \mathrm{mg} / \mathrm{kg} \mathrm{b} / \mathrm{w})$ into the tail vein. After 2 days, glycosuria was detected by urinary glucose strips. Blood samples were withdrawn from the tail vein and the level of glucose was determined by glucose oxidase technique. Animals were sacrificed in regular time intervals one month apart, until their 'natural' death at the age of 5 months.

After 10 years of experience [27] we briefly classify alterations observed for diabetic cataratous eyes as follows:

Degree 0. Healthy eye, transparent lens.

Degree 1. Typical blood vessels dilatation and calibration, transparent lens.

Degree 2. Dilatation and/or caliber irregularities. Deterioration of lens tranparency.

Degree 3. Atrophy of the iris blood vessels up to $1 / 3$. Cataract around $1 / 3$ of the lens.

Degree 4. Atrophy of the iris blood vessels up tp 2/3. Cataract more than $2 / 3$.

Degree 5. Atrophy of the iris blood vessels more than 2/3. Milk-white lens. 
Furić, K., Mohaček-Grošev, V., Hadžija, M. (2005), "Development of cataract caused by diabetes mellitus: Raman study" Journal of Molecular Structure, Vol. 744-747, pp. 169-177.

According to the above given classification, the cataract degree corresponds rather well with the cataract duration measured in months.

\subsection{Lens/sample preparation}

Immediately after the extraction under the low-magnification stereo microscope each pair of the rat lenses was subjected to vibrational spectroscopic study. For Raman spectroscopy one lens globe of every pair was immersed in a rectangular quartz cell with phosphate buffer saline (PBS). Inner dimension of the used cell was slightly smaller than the lens diameter securing a tight contact between cell walls and the lens globe. The contribution of the water conservant (PBS used here) to the Raman scattering from the sample was thus quite negligible. The other lens of each pair was pressed with $\mathrm{KBr}$ to form a pellet for transmission FTIR spectroscopy. Because of high lens tissue toughness, a very thorough milling, several pressings and dilutions were needed. Although special attention was paid to maintenance of reproducibility, the infrared results were not very reliable from hydration point of view. We used them only for monitoring purpose.

\subsection{Raman spectroscopy}

Preliminary Raman measurements have shown the advantage of backscattering as compared with $90^{\circ}$ geometry, particularly for highly developed cataractous samples. Therefore all spectra were recorded in backscattering, focusing the laser beam across the lens globe centre in order to exclude inhomogeneity/directional influence [28]. Since biological material is sensitive to laser irradiation, total beam power at the place of the sample was 100 or $200 \mathrm{~mW}$, chosen as a compromise of signal enhancement and minimization of sample degradation. For the excitation COHERENT argon ion laser model INNOVA 100-15 operating at $514.5 \mathrm{~nm}$ in light-stabilizing mode was used. Spectra were recorded by computerized triple monochromator DILOR model Z24, incorporating a new Peltier-cooled (C31034-A02 RCA/BURLE) photomultiplier. Additional improvement of $\mathrm{S} / \mathrm{N}$ ratio was obtained taking four scans over the 200-1800 and $2500-4000 \mathrm{~cm}^{-1}$ spectral regions, with $4 \mathrm{~cm}^{-1}$ resolution, $1 \mathrm{~cm}^{-1}$ data interval (step size) and accumulation time of $1 \mathrm{~s}$ per data point. Because of daily spectral calibration, wavenumbers are correct within $1 \mathrm{~cm}^{-1}$.

\subsection{Spectra treatment}

Raman vibrational spectra were recorded using original software purchased together with described spectrometer. Another commercial software was used for data and background substraction, transmittance $\rightarrow$ absorbance conversion, and for total and partial integration of vibrational bands.

Two Raman spectra recorded for $200-1800$ and $2500-4000 \mathrm{~cm}^{-1}$ spectral intervals together with infrared spectrum obtained for $400-4000 \mathrm{~cm}^{-1}$ are displayed in Fig. 1. These all refer to a healthy 
Furić, K., Mohaček-Grošev, V., Hadžija, M. (2005), "Development of cataract caused by diabetes mellitus: Raman study" Journal of Molecular Structure, Vol. 744-747, pp. 169-177.

rat lens and represent a comparison of efficiency and complementarities of both vibrational spectroscopic methods. Although spectra were recorded under equivalent resolution circumstances, it is obvious that vibrational bands are much better resolved in Raman spectra. Also, in the middle of the stretching region of water molecule (roughly between 3100 and $3700 \mathrm{~cm}^{-1}$ ) infrared spectral feature is approaching total absorption. Bearing in mind destruction of biological tissue introduced here by $\mathrm{KBr}$ pellet preparation technique, it is obvious that this method is not very suitable for the investigation of the fine water balance in the eye lens.

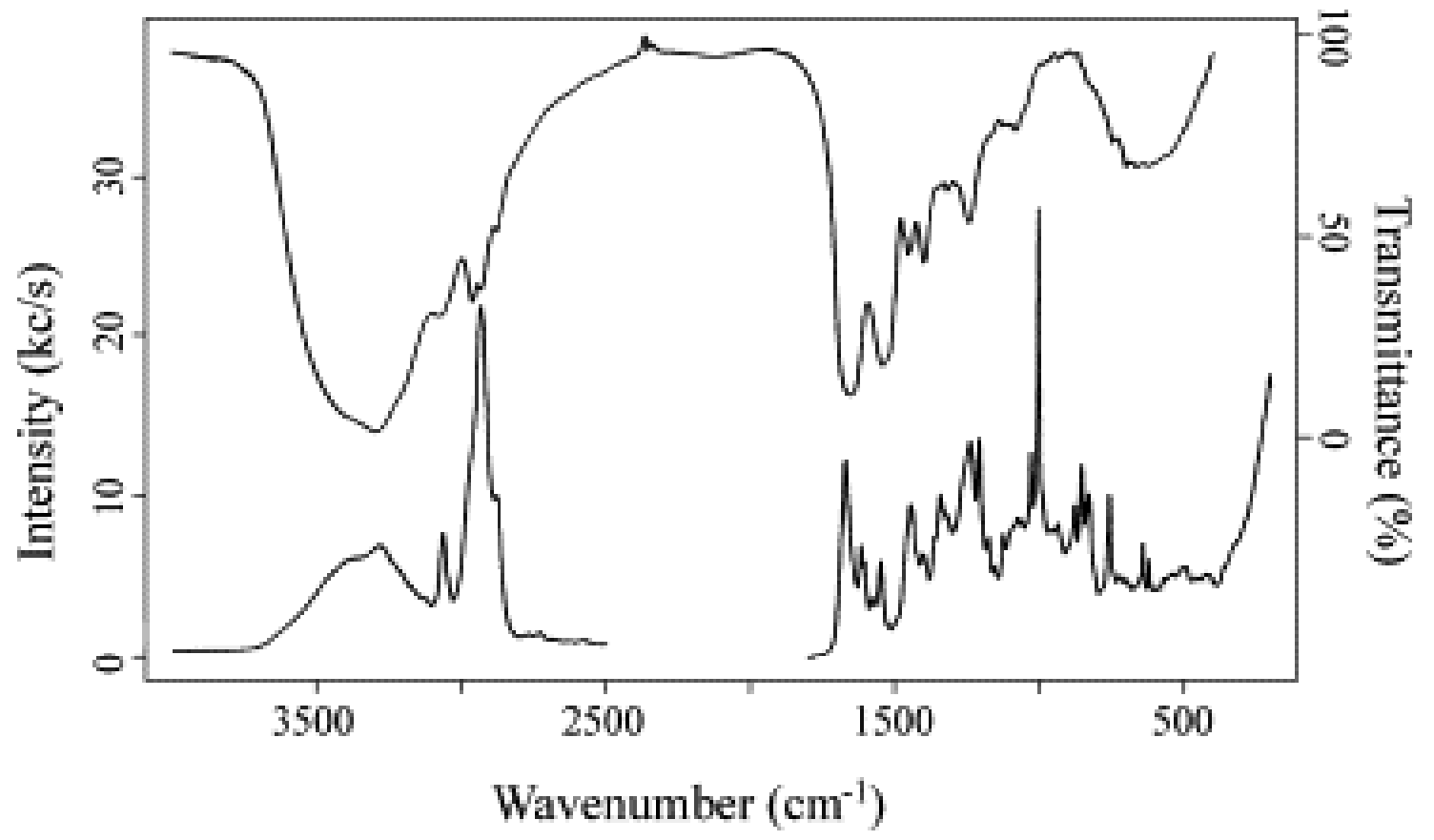

Fig 1 Comparison of infrared (upper curve) and Raman (lower curve) spectra of a healthy rat lens that are used as reference, internal standard in this work. The left ordinate scale in thousands of counts per second relates to parts of Raman spectrum, and the right ordinate scale in percentage of transmittance relates to infrared spectrum.

\section{Results}

\subsection{Disease Progression}

Glucose concentration in all rats with developed alloxan diabetes was higher than $15 \mathrm{mmol} / \mathrm{l}$ (Fig. 2b), although some individual differences were observed. Together with continuous weight loss (Fig. 2a) other common disease characteristics like polydipsia, polyuria, glycosuria (>5\%) and periodical ketonuria were present. In the case of healthy, control animals glycosuria and ketonuria were never observed, and blood glucose was below $5.5 \mathrm{mmol} / \mathrm{l}$ (Fig. 2b) during the whole experiment. 
Furić, K., Mohaček-Grošev, V., Hadžija, M. (2005), "Development of cataract caused by diabetes mellitus: Raman study" Journal of Molecular Structure, Vol. 744-747, pp. 169-177.
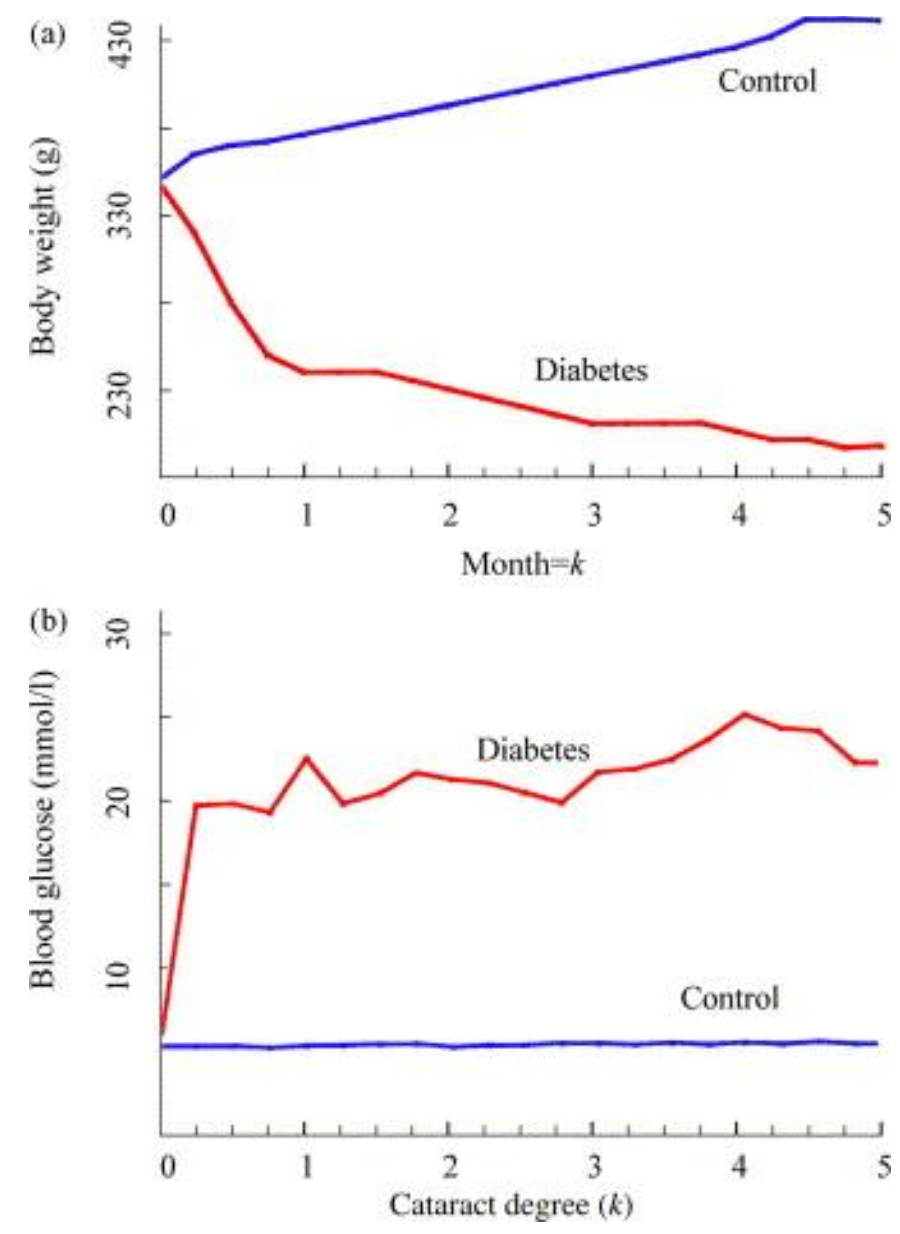

Fig 2 Body weight (a) and blood glucose (b) as a function of time (in months) for healthy and diabetic rats during the experimental period.

\subsection{Main spectral characteristics}

Positions of all vibrational bands observed for clear, healthy rat lens using Raman and infrared spectroscopy are given in first two columns of Table 1 . Together with wavenumbers the shortest description of spectral peculiarities is added for each band. Two spectroscopies give results, which agree rather well, considering widths of infrared bands. In the third column, that includes a tentative assignment of observed bands, we try to compromise our consideration with opinions of other research groups (for some spectral regions not perfectly in accord, see for example Refs. [9], [10], [11] and [29]. 
Furić, K., Mohaček-Grošev, V., Hadžija, M. (2005), "Development of cataract caused by diabetes mellitus: Raman study" Journal of Molecular Structure, Vol. 744-747, pp. 169-177.

Table 1 Wavenumbers (in $\mathrm{cm}^{-1}$ ) of Raman and infrared observed bands of a healthy rat lens with a tentative assignment and short description of band profiles

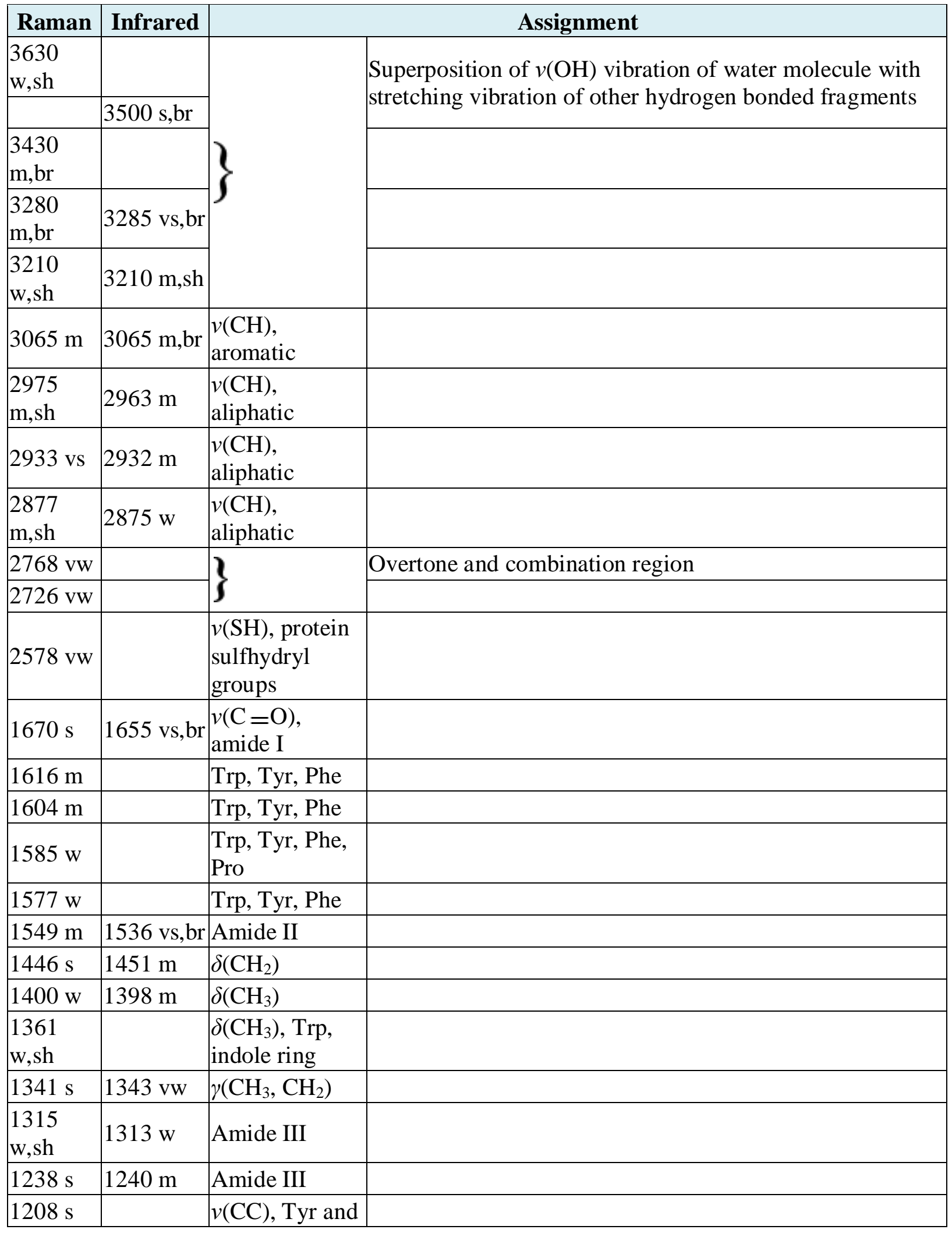


Furić, K., Mohaček-Grošev, V., Hadžija, M. (2005), "Development of cataract caused by diabetes mellitus: Raman study" Journal of Molecular Structure, Vol. 744-747, pp. 169-177.

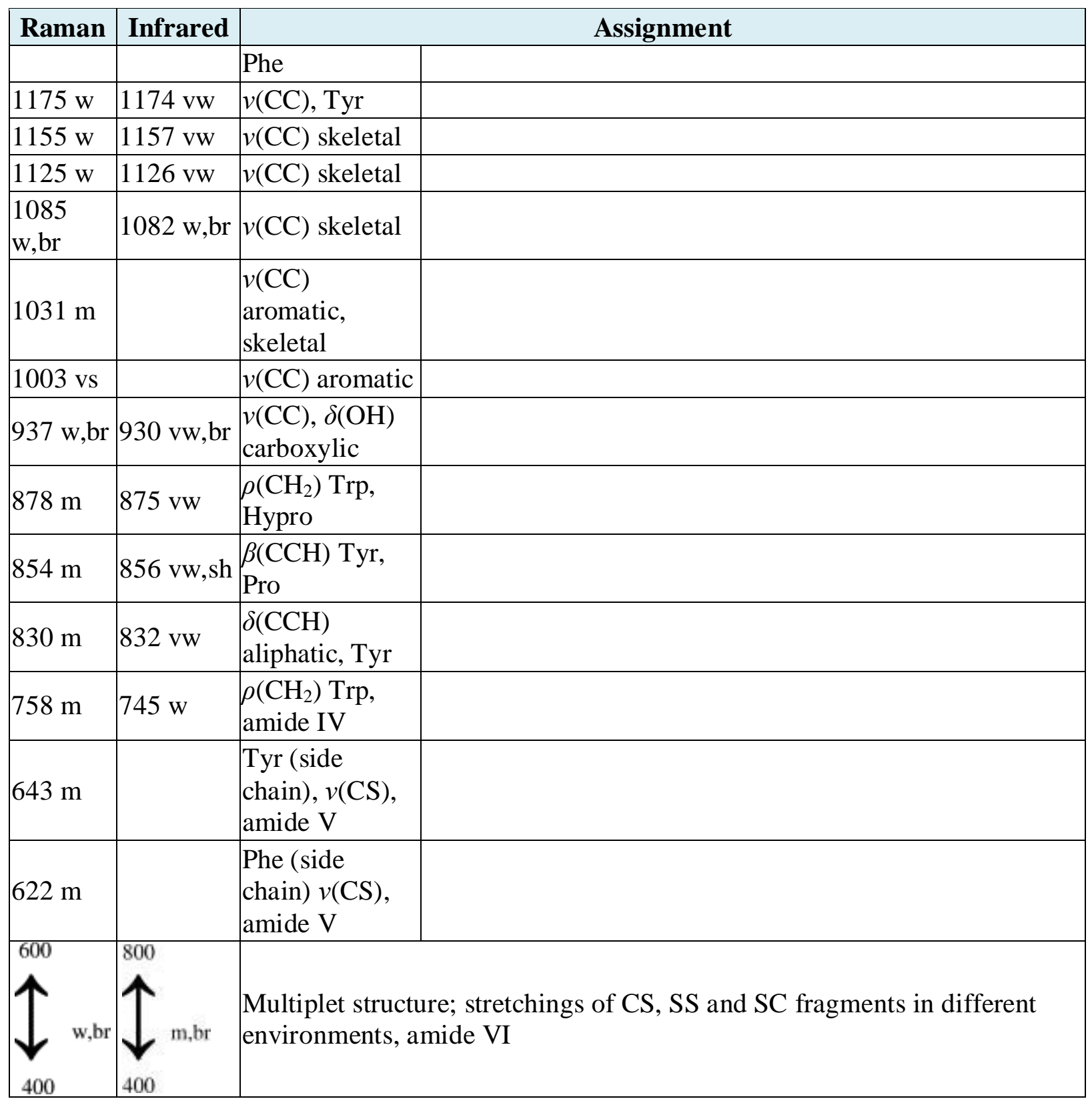

$\mathrm{v}$, very; w, weak; m, medium; s, strong; br, broad; sh, shoulder; $v$, stretching; $\beta$, in plane bending; $\rho$, rocking; $\gamma$, wagging; $\delta$, deformation; Phe, phenylalanine; Tyr, tyrosine; Trp, tryptophan; Pro, proline; Hypro, hydroxyproline.

The main water band region between 3100 and $3700 \mathrm{~cm}^{-1}$ was investigated in a number of studies, sometimes using polarization analysis. Two important bands of comparable intensity are always observed together with two shoulders. It is well known that strong band at lower frequency side changes it intensity depending on the concentration of dissolved matter. This effect, observed for both inorganic and organic water solutions [30], [31] and [32] is explained in terms of Fermi resonance and in the same context will be considered later here. Spectral interval $2500-3100 \mathrm{~cm}^{-1}$ includes aromatic and aliphatic $\mathrm{C}-\mathrm{H}$ stretching, stretching of protein sulfhydril groups and few very weak combination bands. 
Furić, K., Mohaček-Grošev, V., Hadžija, M. (2005), "Development of cataract caused by diabetes mellitus: Raman study" Journal of Molecular Structure, Vol. 744-747, pp. 169-177.

Below $1700 \mathrm{~cm}^{-1}$ there are many vibrational modes whose assignment is not straightforward. Most prominent amid bands (I and II) are easily recognised while assignment of other characteristic amide bands (for example amide III) is less certain. The overlap of different assignments of vibrational bands characterizing different molecular subgroups is particularly pronounced for skeletal side chain, amide side chain and disulphide-amide pairs.

After the preliminary vibrational spectroscopic investigation of a healthy rat lens, summarized in Fig. 1 and Table 1, cataractous cases were studied in ascending order of deterioration degree. Fig. 3 and Fig. 4 illustrate important spectral changes for the degree of cataract denoted +2 , 4 and 5 . Lower degrees of cataract, between 0 and +2 , gave so similar spectra that no changes were identified even with spectra differentiation. Once the cataract degree approaches +2 , several new characteristics are noticeable. The first one, the signal to noise ratio deterioration, is a direct consequence of the loss of lens transparency and is observed for the whole spectral region. Another one is the increase of the background fluorescence whose level and spectral shape significantly change depending on cataract duration. Finally, it is important to notice the growth

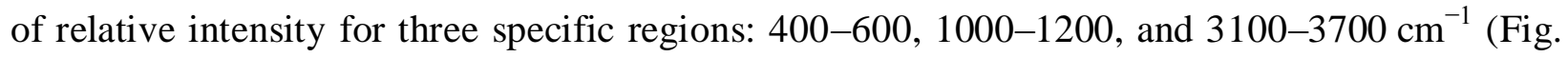
3 and Fig. 4). To quantify these changes, two indices were introduced that characterize diseased lenses from spectroscopic point of view.

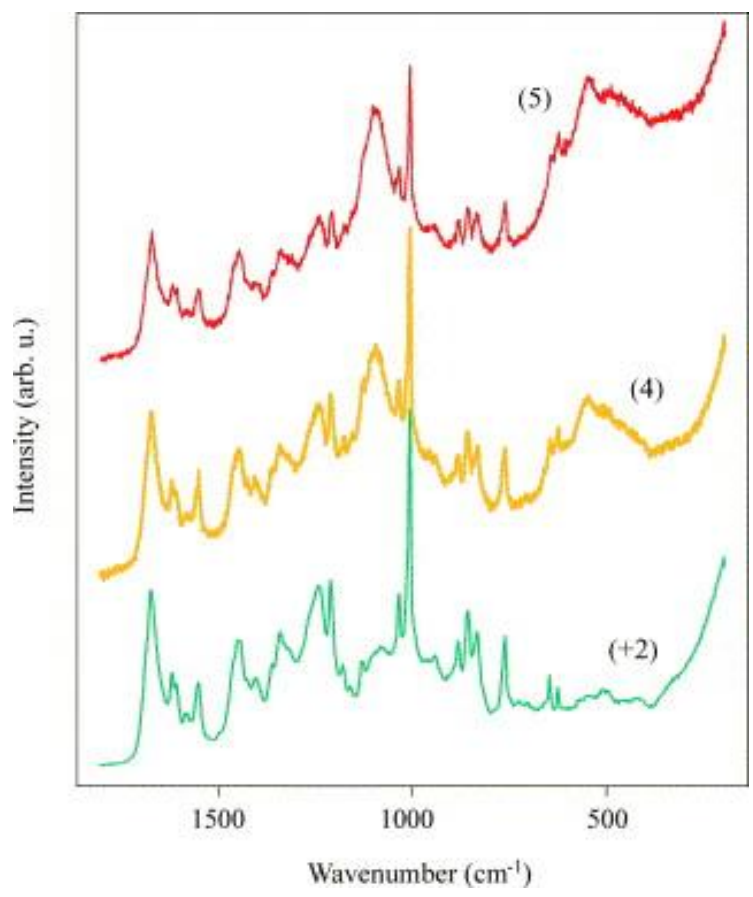

Fig 3 Raman spectra of cataractous rat lens $\left(200-1800 \mathrm{~cm}^{-1}\right)$. The cataract degree is shown in parenthesis. 
Furić, K., Mohaček-Grošev, V., Hadžija, M. (2005), "Development of cataract caused by diabetes mellitus: Raman study" Journal of Molecular Structure, Vol. 744-747, pp. 169-177.

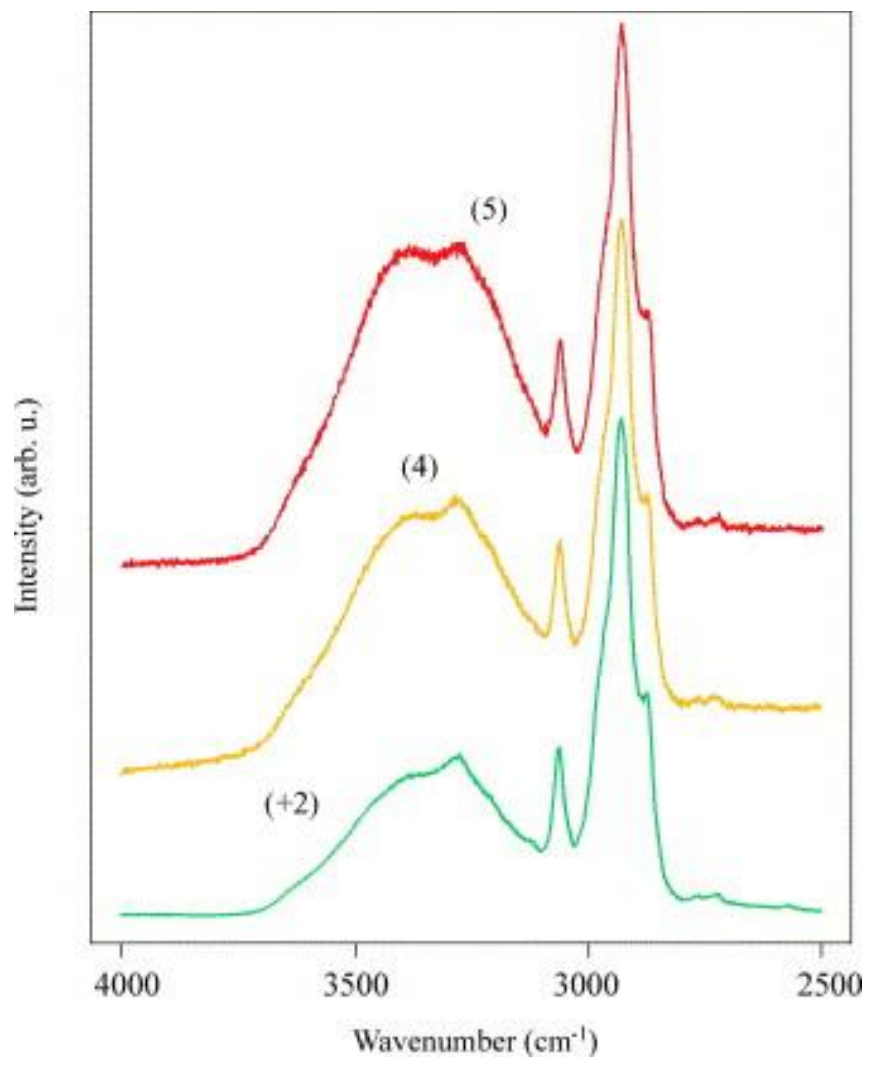

Fig 4 Raman spectra of cataractous rat lens $\left(2500-4000 \mathrm{~cm}^{-1}\right)$. The cataract degree is shown in parenthesis.

3.3. Fluorescence-background index $\left(F_{\mathrm{FB}}\right)$

A spectral record for the $k$ th cataract degree, more precisely the intensity distribution versus wavenumbers (in counts/data point/accumulation time) is denoted here as $I^{k}\left(v^{-}\right)$. The spectrum of the healthy lens ( $k=0$ in our notation) possesses the lowest background fluorescence level (we would say zero) and naturally is used as a reference spectrum. Spectra of cataractous lenses are characterized by higher fluorescence-background level. Therefore, the spectrum of diseased lens $I^{k}\left(v^{-}\right)$(where $\left.k \neq 0\right)$ can be easily resolved in two contributions

$$
I^{k}(\bar{v})=\begin{aligned}
& I_{\mathrm{R}}^{k}(\bar{v})=c_{K} I^{0}(\bar{v}) \\
& I_{\mathrm{BF}}^{k}(\bar{v})=I^{k}(\bar{v})-c^{k} I^{0}(\bar{v})
\end{aligned}
$$

using some software suitable for one-dimensional treatment. The upper term describes pure Raman contribution (healthy lens) to the total scattering intensity and lower term can be assigned to background-fluorescence contribution. To put it another way, when the constant $c^{k}$ is properly chosen, pure Raman scattering contribution is minimised (suppressed) in the diseased lens spectrum. Fig. 5 shows an example of such spectral treatment for the cataract degree equal to 3 . We introduce the fluorescence-background index 
Furić, K., Mohaček-Grošev, V., Hadžija, M. (2005), "Development of cataract caused by diabetes mellitus: Raman study" Journal of Molecular Structure, Vol. 744-747, pp. 169-177.

$$
F_{\mathrm{FB}}^{k}=\frac{\int_{A}^{B} I_{\mathrm{BF}}^{k}(\bar{v}) \mathrm{d} \bar{v}}{\int_{A}^{B} I_{\mathrm{R}}^{k}(\bar{v}) \mathrm{d} \bar{v}}=\frac{\int_{A}^{B} I_{\mathrm{BF}}^{k}(\bar{y}) \mathrm{d} \bar{\nu}}{c^{k} \int_{A}^{B} I^{0}(\bar{\nu}) \mathrm{d} \bar{v}}
$$

as the ratio of two integral values. It is in fact the integral value of fluorescence-background contribution normalised by integral value of Raman contribution, both over the same A-B spectral interval. In Fig. $5 \mathrm{FB}$ contribution (numerator in the $F_{\mathrm{FB}}$ definition) is equal to the area below lower (b) spectrum and Raman contribution (denominator in the $F_{\mathrm{FB}}$ definition) is equal to the area between two ( $\mathrm{a}$ and $\mathrm{b}$ ) spectra. In this study two A-B intervals were analyzed (200-1800 and 2500-4000 $\mathrm{cm}^{-1}$ ); results for both are displayed in Table 2 and Fig. 6.

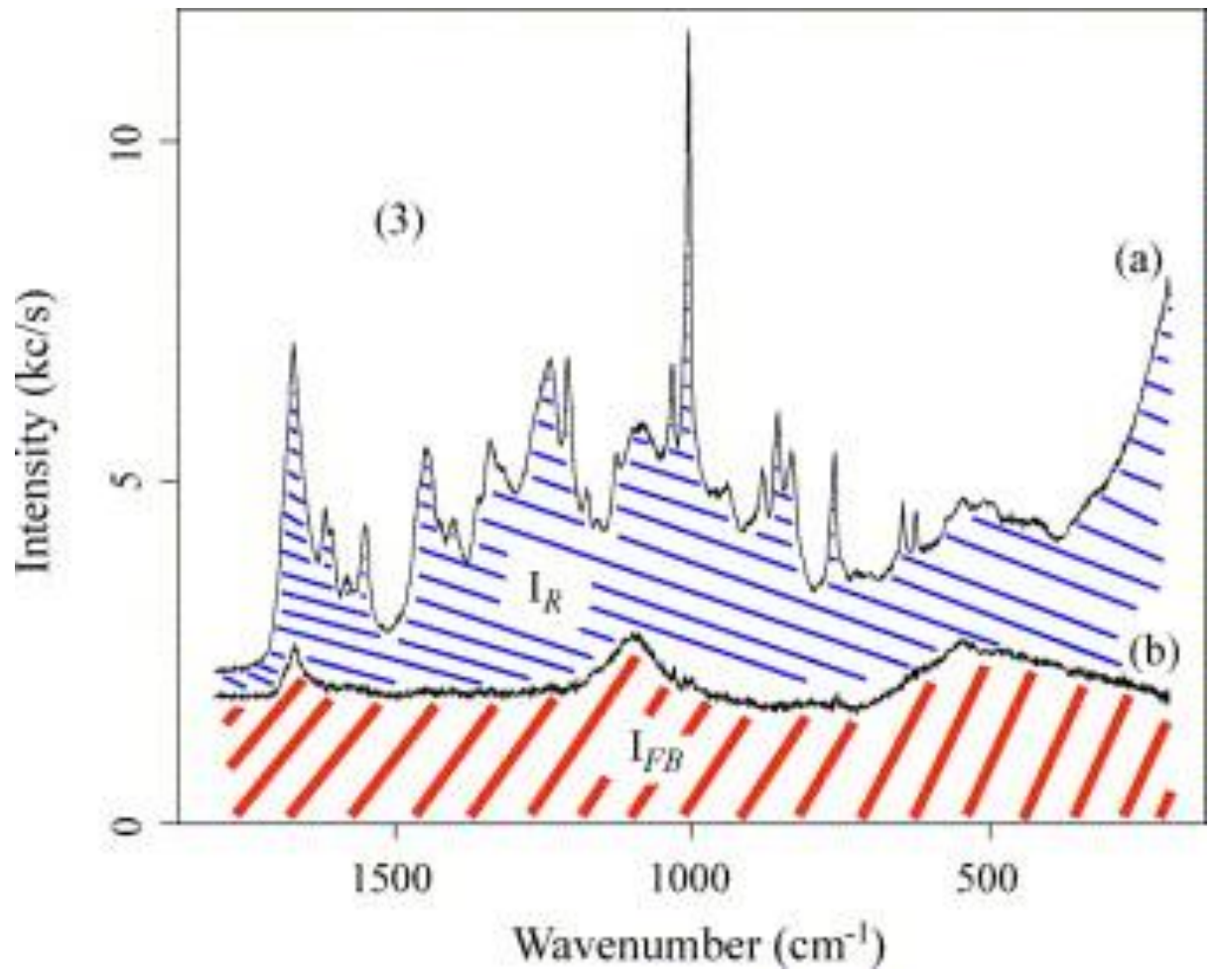

Fig 5 Determination of background-fluorescence index $\left(F_{\mathrm{FB}}\right)$. Upper $(\mathrm{a})$ spectrum is the original record obtained on lens having the third degree of cataract. Lower (b) spectrum is the background-fluorescence leftover after best suppression of the Raman spectrum of healthy lens has been achieved. 
Furić, K., Mohaček-Grošev, V., Hadžija, M. (2005), "Development of cataract caused by diabetes mellitus: Raman study" Journal of Molecular Structure, Vol. 744-747, pp. 169-177.

Table 2 Fluorescence background index $\boldsymbol{F}_{\mathrm{FB}}$ and water band index $\boldsymbol{F}_{\mathrm{W}}$ determined using Raman spectroscopy for rat lenses with different degree of cataractous degradation (definitions are given in the text)

\begin{tabular}{|c|c|c|c|}
\hline \multirow{2}{*}{$\begin{array}{l}\text { Cataract degree } \\
\qquad(k=\text { month) }\end{array}$} & \multicolumn{2}{|c|}{$\begin{array}{l}\text { Fluorescence background index }\left(F_{\mathrm{FB}}\right) \text { for } \\
\text { interval }\end{array}$} & \multirow{2}{*}{$\begin{array}{l}\text { Water band index } \\
\left(F_{\mathrm{w}}\right)\end{array}$} \\
\hline & $\begin{array}{c}200- \\
1800 \mathrm{~cm}^{-1}\end{array}$ & $2500-4000 \mathrm{~cm}^{-1}$ & \\
\hline 0 & 0 & 0 & 1 \\
\hline 1 & 0.10 & -0.02 & 1.00 \\
\hline-2 & 0.07 & 0.05 & 1.05 \\
\hline 2 & a & $\mathrm{a}$ & $\mathrm{a}$ \\
\hline+2 & 0.07 & 0.07 & 1.08 \\
\hline 3 & 0.83 & 0.84 & 1.28 \\
\hline 4 & 6.58 & 2.80 & 1.68 \\
\hline 5 & 3.47 & 1.70 & 2.16 \\
\hline
\end{tabular}

a These values were not determined during the main course of the experiment due to a sudden failure of the Raman instrument. After the instrument reparation the sample [2] deteriorated completely, and the experiment was repeated with new samples (see the results for cataract degrees $(-2)$ and $(+2) ; 1$ week before and one after the second month). 
Furić, K., Mohaček-Grošev, V., Hadžija, M. (2005), "Development of cataract caused by diabetes mellitus: Raman study" Journal of Molecular Structure, Vol. 744-747, pp. 169-177.

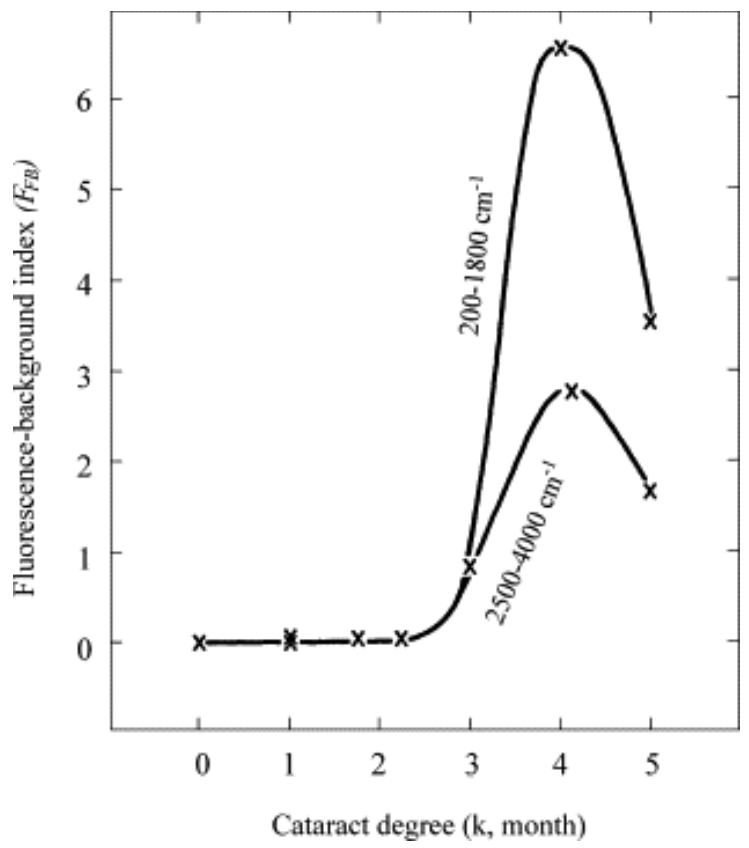

Fig 6 Dependence of background-fluorescence index $\left(F_{\mathrm{FB}}\right)$ on the degree of cataract changes. Two curves obtained over different spectral intervals possess the same general behaviour.

3.4. Water band index $F_{\mathrm{W}}$

In an attempt to improve understanding of fine water balance, probably one of the crucial properties of the living tissue, the $\mathrm{O}-\mathrm{H}$ stretching region was carefully studied. As a second measure of cataract changes we introduce water band index

$$
F_{\mathrm{W}}=\frac{\int_{B}^{C} I^{k}(\bar{\nu}) \mathrm{d} \bar{\nu}}{\int_{A}^{B} I^{k}(\bar{\nu}) \mathrm{d} \bar{\nu}}
$$

where $A, B, C$ integration limits border a water band $\mathrm{O}-\mathrm{H}$ region $\left(B C=3100-3700 \mathrm{~cm}^{-1}\right)$ and a protein $\mathrm{C}-\mathrm{H}$ region $\left(A B=2800-3100 \mathrm{~cm}^{-1}\right)$ as shown by Fig. 7 . It is necessary now to frame a background problem. The simplest approach would be integration above $A B$ and $B C$ straight lines, but it leaves important triangular $(A B C)$ area not attributed. Without highly sophisticated tools needed for spectral resolving of many broad and close bands, we solved the problem by integrating both intervals $A B$ and $B C$ above the common $A C$ straight line. In this way triangular background area was spread in approximately $2: 1$ ratio favorizing $\mathrm{O}-\mathrm{H}$ against $\mathrm{C}-\mathrm{H}$ contribution. These two simple methods give for the same spectral record numerically different results. However, general feature of $F_{\mathrm{W}}$ dependence on cataract degree is the same for both cases, and the second approach was chosen for further discussion. To simplify mutual comparison, results obtained for all cataractous cases were normalised to the healthy lens value, as displayed in Table 2 and Fig. 8. 
Furić, K., Mohaček-Grošev, V., Hadžija, M. (2005), "Development of cataract caused by diabetes mellitus: Raman study" Journal of Molecular Structure, Vol. 744-747, pp. 169-177.

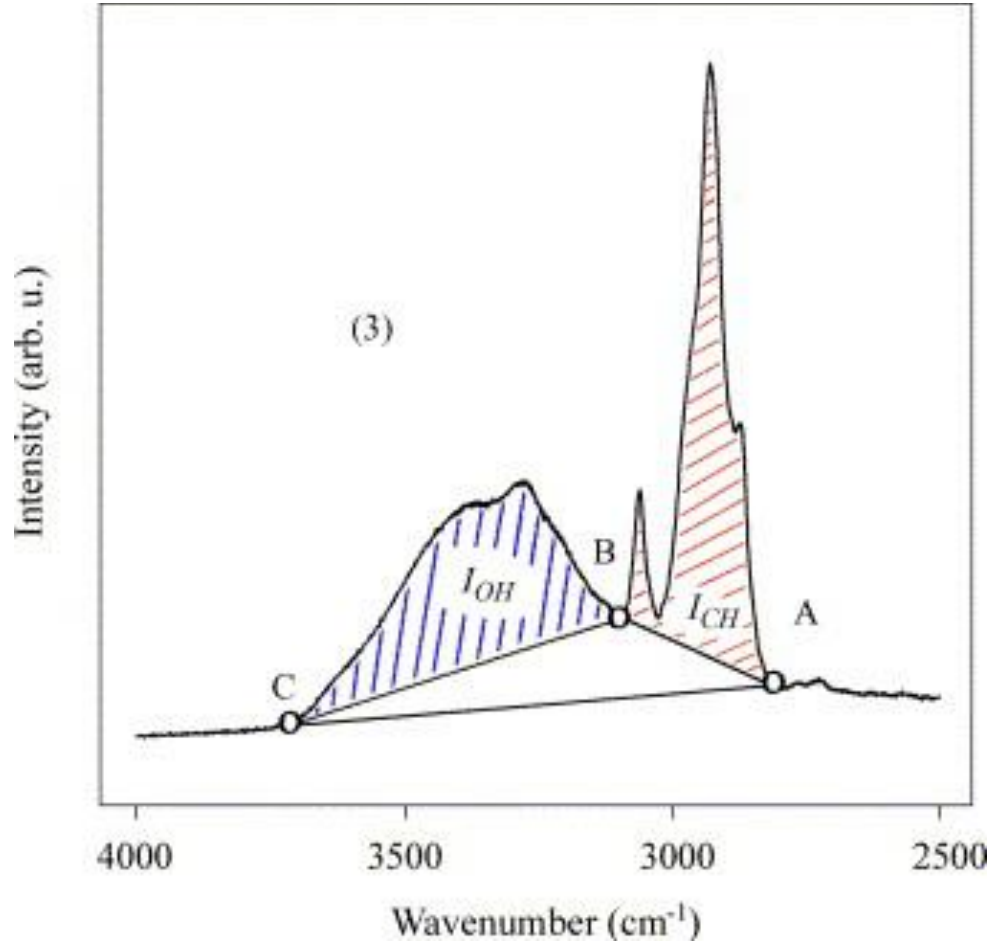

Fig 7 Determination of water band index $\left(F_{\mathrm{W}}\right)$. Points $A, B$ and $C$ important for partial integration are taken at 2800,3100 and $3730 \mathrm{~cm}^{-1}$. Higher frequency $(B C)$ interval covers water molecule stretching region, lower frequency $(A B)$ interval is assigned to protein $\mathrm{C}-\mathrm{H}$ stretching region.

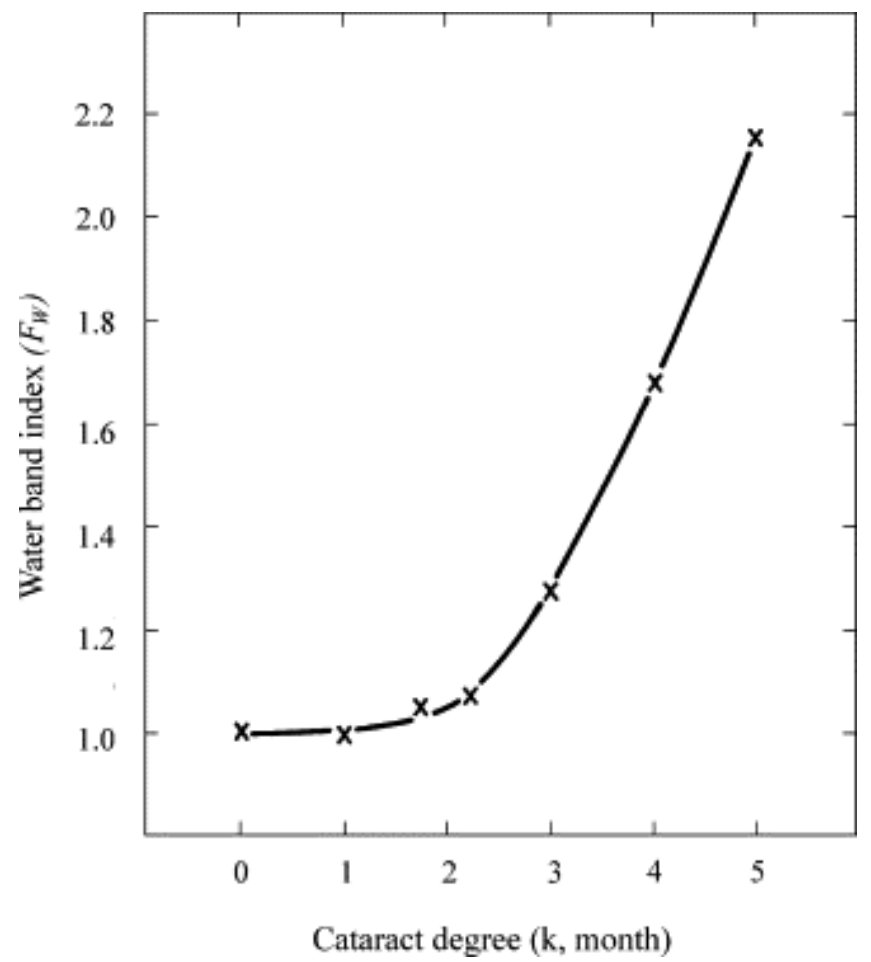

Fig 8 Dependence of water band index $\left(F_{\mathrm{W}}\right)$ on the degree of cataract changes. 
Furić, K., Mohaček-Grošev, V., Hadžija, M. (2005), "Development of cataract caused by diabetes mellitus: Raman study" Journal of Molecular Structure, Vol. 744-747, pp. 169-177.

\section{Discussion}

Studying laboratory induced (experimental) diabetes provides many opportunities for development and investigation of secondary complications. Non-enzymatic glycosylation of lens proteins is involved in cataractogenesis and other diabetic complications [21], [22], [23], [24] and [33]. Besides glucose some other compounds (fructose, fructose-3-phosphate, glucose6-phosphate, glucosamine, ribose) participate in this process [34] and [35], and efforts have been made to evaluate the modification done to lens proteins by glycation-induced crosslinking [24]. Here we try to elucidate the mechanism underlying cataract development by finding correlations between spectral changes in diseased lenses and protein sites most prone to glycosylation.

According to their molecular mass, crystallins in the lens are labeled $\alpha\left(M_{\mathrm{r}}=750,000-\right.$ $1,200,000 \mathrm{~g} / \mathrm{mol}), \beta\left(M_{\mathrm{r}} \approx 180000 \mathrm{~g} / \mathrm{mol}\right)$ and $\gamma\left(M_{\mathrm{r}} \approx 20,000 \mathrm{~g} / \mathrm{mol}\right)$ crystallins [36]. The majority of those present (45\%) are $\alpha$ crystallins which act as chaperons, that is, they prevent aggregation of smaller crystallins above $30{ }^{\circ} \mathrm{C}$ [37]. For some crystallins the $\mathrm{X}$ ray structure is determined, such as for calf $\gamma$ II crystallin [38]. This protein has two domains with large amount of sulfhydryl groups and no disulfide bonds in the native state [39]. Fourier transform infrared spectroscopy confirmed the majority of secondary structure in lens proteins to be in the form of $\beta$ pleated sheet, which gives origin to the strong $1670 \mathrm{~cm}^{-1}$ infrared amide I band [40]. Scanning electron microscopy of human lenses belonging to various age groups was employed for better understanding of tertiary and quaternary structure of protein fibers and membrane layers as well [2]. Raman microscopic study, also done on human lenses, concentrated on distribution of tyrosine and tryptophane amino acids in different sections of the lens [41]. What happens during cataract progression?

Our two integrated intensity ratios that were defined (background-fluorescence index and water band index) both have small value at the beginning of disease, until the cataract degree equal to 2 is approached (approx. 2 months later). A sudden increase in all indices is then observed, as shown in Fig. 6 and Fig. 8 and Table 2, followed by a common steady increase until the cataract degree equals 4 . After that point the water band index continues its exponential-like increase, but the background-fluorescence index drops. At the first glance this is an embarrassing controversy, but once the diabetic cataractous process is understood, a simple explanation seems plausible.

We give here a model describing the main course of the studied disease. During very early stage of cataract, hydrated molecules of glucose start to stick to protein sheet, forming glycosidic bonds at certain locations. The most probable targets would be molecular groups which are known to bind to sugars in glycoproteins and proteoglycans-if $O$-glycosidic linkage is to be formed, than an $\mathrm{O}-\mathrm{H}$ group such as in tyrosine is likely candidate, and for lens proteins abundant in reactive sulfhydryl groups it is possible that $\mathrm{S}$-glycosidic linkages take place [42]. A strong Raman band at $1100 \mathrm{~cm}^{-1}$ corresponds to freshly formed $\mathrm{C}-\mathrm{O}$ bonds, while $\mathrm{C}-\mathrm{S}$ bonds have their counterpart in the broad band at $540 \mathrm{~cm}^{-1}$ which gains on intensity as the disease progresses 
Furić, K., Mohaček-Grošev, V., Hadžija, M. (2005), "Development of cataract caused by diabetes mellitus: Raman study" Journal of Molecular Structure, Vol. 744-747, pp. 169-177.

(Fig. 4). These products of Maillard reaction also act as fluorophors, giving rise to fluorescence which completely screens out Raman signal in later stages of cataract.

Each glucose molecule binds water, so the amount of water chelated to glycated protein increases. Since crystallin is among the most durable proteins in living beings, it seems likely that water agglomerates in pockets between fibers without protein breaking. This would explain why it is possible to decompose each Raman spectrum of diseased lens into a 'healthy' spectrum and fluorescent background contribution. These water agglomerates contribute to 3100$3700 \mathrm{~cm}^{-1}$ spectral interval more and more (Fig. 3) as the cataract progresses and the water band index rises sharply (Fig. 8). The accumulation of water takes place in the cortex first, that is in the part most distant from the lens nucleus, and in the part in which cells are youngest and still dividing. Earlier electron microscopy findings of other groups together with our preliminary results obtained using light microscopy also support the model proposed.

\section{Conclusion}

Raman spectroscopy has been employed in the study of healthy and cataractous rat lenses. The cataract was the result of progressive diabetes mellitus caused by an alloxan injection in rats tail vein. From spectral changes observed during 5 months of disease follow-up, we conclude that agglomeration of water to small sugar molecules which bind to crystallin fibers and possibly other proteins is the main cause of diabetic cataract. Raman spectroscopic investigation presented in this work can be resumed by simplified model within them three different mechanisms has been resolved (Fig. 9). Inside of the cataractous lens there are completely transparent parts of the healthy tissue where light rays follow simple Snell's rule of diffraction contributing to the sharp image in the focal plane (annotated as regular in the same figure). Some of the rays, passing the lens, scatter on the fluorescent centers changing the own wavelength and the direction (lower trace in the same figure). The third mechanism (the lowest ray in Fig. 9) is also scattering process but this one develops on water agglomerates possessing an index of refraction very similar to those of crystallin. In this case the light rays change their direction but not the color. Of course, the second and the third mechanism deteriorate a sharp view (which is characteristic of a healthy lens), but not on the equal footing. Our early but not proved experience says that the fluorescence centers are more responsible for an aged cataract, while water agglomerates contribute dominantly to the diabetic cataract. It is highly probable that both processes are present in all cases. 
Furić, K., Mohaček-Grošev, V., Hadžija, M. (2005), "Development of cataract caused by diabetes mellitus: Raman study" Journal of Molecular Structure, Vol. 744-747, pp. 169-177.

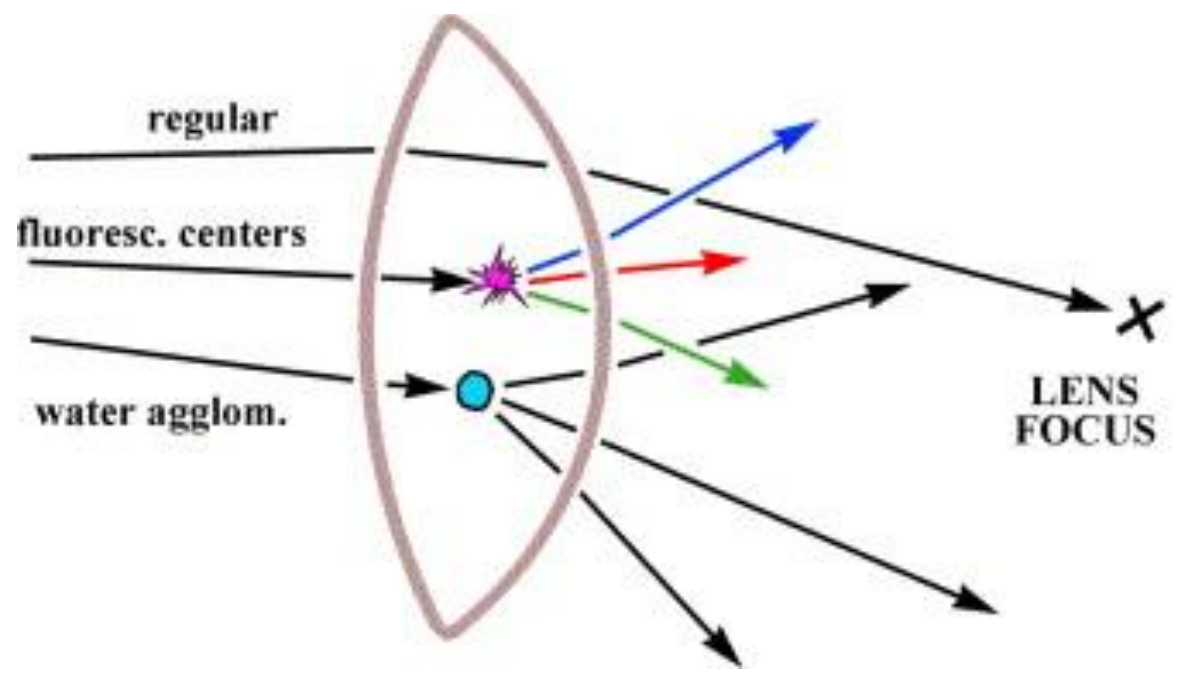

Fig 9 Light refraction and light scattering inside of the eye lens. Three different mechanisms are resolved using Raman spectroscopy.

\section{Acknowledgments}

This work was supported by Ministry of Science, Education and Sport of the Republic of Croatia, grants No. 0098022,0098019 and 00981109.

\section{References}

[1] A.I. Deyev, M.A. Babizhayev, Biol. Membr. 19 (5) (2002) 435.

[2] K.J. Al-Ghoul, R.K. Nordgren, A.J. Kuszak, C.D. Freel, M.J. Costello, J.R. Kuszak, Exp. Eye Res. 72 (2001) 199.

[3] J.A. Mannino, Human Biology, Mosby-Year Book, Inc., St Louis, USA, 1995.

[4] R.A. Quinlan, A. Sandilands, J.E. Procter, A.R. Prescott, A.M. Hutcheson, R. Dahm, C. Gribbon, P. Wallace, J.M. Carter, Eye 13 (1999) 409-416.

[5] A. Mahadevan-Jensen, H.H. Mantsch, G.J. Puppels (Eds.), Proc. SPIE Vol. 4614 (2002): Biomed. Vib. Spectrosc. II (2002).

[6] L.P. Choo-Smith, H.G.M. Edwards, H.P. Endtz, J.M. Kros, F. Heule, H. Barr, J.S. Robinson Jr., H.A. Bruining, G.J. Puppels, Biopolymers (Biospectroscopy) 67 (2002) 1-9.

[7] R.J. Erckens, F.H.M. Jongsma, J.P. Wicksted, F. Hendrikse, W.H. March, M. Motamedi, Lasers Med. Sci. 16 (2001) 236.

[8] E.E. Lawson, B.W. Barry, A.C. Williams, H.G.M. Edwards, J. Raman Spectrosc. 28 (1997) 111.

[9] S.F. Parker, Applications of infrared, Raman and Resonance Raman spectroscopy in Biochemistry, Plenum Press, New York, 1983.

[10] N.-T. Yu, X.Y. Li (Eds.), Proceedings of XIV International Conference on Raman Spectroscopy, Hong Kong 22-26 Aug, 1994, Wiley, Chichester, 1994. 
Furić, K., Mohaček-Grošev, V., Hadžija, M. (2005), "Development of cataract caused by diabetes mellitus: Raman study" Journal of Molecular Structure, Vol. 744-747, pp. 169-177.

[11] A. Bertoluzza, C. Fagnano, P. Monti, Proceedings of the the Third European Conference on Spectroscopy of Biological Molecules, Bologna 1989, Societa Editrice Esculapio 1989.

[12] R.C. Lord, N.-T. Yu, J. Mol. Biol. 50 (1970) 509.

[13] S. Krimm, Y. Abe, Proc. Natl Acad. Sci. USA 69 (1972) 2788.

[14] J.L. Konig, B.G. Frushour, Biopolymers 11 (9) (1972) 1871.

[15] R.A. Schahar, S.A. Solin, Invest. Ophtalmol. 14 (1975) 380.

[16] A. Bertoluzza, C. Fagnano, P. Monti, G. Semerano, J.V. Garcia-Ramos, R. Caramazza, M. Cellini, J. Raman Spectrosc. 18 (1987) 151.

[17] D.C.W. Siew, G.M. Glover, R.P. Cooney, P.M. Wiggins, J. Raman Spectrosc. 26 (1995) 3.

[18] J. Kinoshita, L. Merola, K. Satoh, E. Dikmark, Nature 194 (1962) 1085.

[19] S. Hayman, J. Kinoshita, J. Biol. Chem. 240 (1965) 877.

[20] A. Sigma, Metabolism 32 (1983) 106.

[21] V.J. Stevens, C.A. Rouzer, V.M. Monnier, A. Cerami, Proc. Natl Acad. Sci. USA 75 (1978) 2918.

[22] P.E. Morgan, R.T. Dean, M.J. Davies, Arch. Biochem. Biophys. 403 (2002) 259.

[23] T.D. Lehman, B.J. Ortweth, Biochim. Biophys. Acta 1535 (2001) 110.

[24] K.-W. Lee, G. Simpson, B. Ortweth, Biochim. Biophys. Acta 1453 (1999) 141.

[25] H.F. Bunn, Am. J. Med. 70 (1981) 325.

[26] F.G. Njoroge, L.M. Sayre, V.M. Monnier, Carbohydr. Res. 167 (1987) 211.

[27] N. Ugrinovic', M. Sljepc`evic', M. Hadžija, B. Jamnicky, Diab. Croat. 20 (1991) 139.

[28] J.F.R. Kuck, N.-T. Yu, Exp. Eye Res. 27 (1978) 737.

[29] R. Mathies, N.-T. Yu, J. Raman Spectrosc. 7 (1978) 349.

[30] F. Rull, J.A. De Saja, J. Raman Spectrosc. 17 (1986) 167.

[31] K. Furic', V. Mohaček, M. Bonifac`ic', I. S` tefanic', J. Mol. Struct. 267 (1992) 39.

[32] D.C.W. Siew, R.P. Cooney, M.J. Taylor, P.M. Wiggins, J. Raman Spectrosc. 25 (1994) 727.

[33] H.A. Kramps, H.J. Hoenders, J. Wollensak, Biochim. Biophys. Acta 434 (1976) 32.

[34] J.J. Harding, Cataract: Biochemistry, Epidemiology and Pharmacology, Chapman \& Hill, London, 1991.

[35] S. Lal, B.S. Szwergold, A.H. Taylor, W.C. Randall, F. Kappler, K. Wells-Knecht, J.W.

Baynes, T.R. Brown, Arch. Biochem. Biophys. 318 (1995) 191.

[36] M. Delaye, A. Tardieu, Nature 302 (1983) 415.

[37] B.Raman,T.Ramakrishna,Ch.M. Rao, J. Biol.Chem. 270 (1995) 19888.

[38] G. Wistow, B. Turnell, L. Summers, C. Slingsby, D. Moss, L. Miller, P. Lindley, T. Blundell, J. Biol. Chem. 170 (1983) 175.

[39] W. Chen, S. Nie, J.F.R. Kuck, N.-T. Yu, Biophys. J. 60 (1991) 447.

[40] S.-Y. Lin, S.-M. Lee, M.-J. Li, R.-C. Liang, Spectrochim. Acta A 53 (1997) 1507.

[41] M.H. Smeets, G.F.J.M. Vrensen, K. Otto, G.J. Puppels, J. Greve, Biochim. Biophys. Acta 1164 (1993) 236.

[42] Y. Ho, F.-Y. Huang, J. Chin. Chem. Soc. 49 (2002) 283. 